\title{
O som expandido: os novos espaços do som no cinema
}

\author{
Expanded sound: new spaces of sound in films
}

\author{
José Cláudio Siqueira Castanheira
}

Doutorando em Comunicação Social pela Universidade Federal Fluminense (UFF), professor do curso de cinema da Universidade Federal de Santa Catarina (UFSC), Florianópolis, SC - Brasil, e-mail: jcscastanheira@gmail.com

\section{Resumo}

Este trabalho analisa como a emergência de novas tecnologias de som no âmbito do cinema levou a uma reconfiguração do espaço de exibição, modificando modelos estabelecidos de escuta. Dispositivos como o Dolby ou o THX - em uma evolução do modelo sonoro monofônico para um estereofônico e, posteriormente, surround - demonstram uma experiência guiada pela ideia de imersão. Novas mídias digitais criam novas demandas cognitivas. Um maior engajamento do corpo é requerido. As ideias de cinema como evento, de um novo espaço idealizado pelas tecnologias de som ou de um espaço sonoro compacto, por autores como Altman, Chion e Langkjær, nos ajudam a pensar esse novo cenário.

Palavras-chave: Cinema. Tecnologias do som. Modelos de escuta.

\section{Abstract}

This paper analyzes how the emergence of new sound technologies within cinema has led to a reconfiguration of exbibition space, changing established ways of listening. Apparatus such as Dolby or THX - the very expansion of a monaural reproduction model to a stereo model and then to a surround sound one - demonstrate an experience guided by the idea of immersion. New digital media create new cognitive demands. A greater engagement of the body is required. The ideas of cinema as an event, of a new space idealized by sound technologies or of a compact sound space, by authors such as Rick. Altman, Michel Chion and Birger Langkjar, help us to think about this new scenery.

Keywords: Cinema. Sound technologies. Listening models. 


\section{Introdução}

A tentativa de construção de novos espaços na experiência cinematográfica - que não apenas aqueles visíveis na tela - certamente não é algo novo na história do cinema. $\mathrm{O}$ apelo a uma sinestesia mais ampla, em que cheiros, texturas e mesmo gostos intensificam e modificam percepções auditivas e visuais, remonta ao próprio início das projeções de imagens em movimento. Por conta de uma hierarquização específica entre sons e imagens, estabelecendo determinado modelo predominante de narrativa, tais relações intersensoriais vão deixando o centro das discussões sobre cinema, pautadas então por exercícios de análise fílmica de um caráter mais hermenêutico. Contudo, a sensação de que o cinema sempre teve mais a transmitir do que apenas uma história com início, meio e fim nunca nos abandonou. A noção de realismo, até hoje uma das referências maiores na experiência cinematográfica, atravessou diversas mudanças, mas sempre esteve presente, exercendo forte influência sobre a ideia que fazíamos da própria natureza do cinema. Essa demanda exacerbada de realismo foi em parte responsável pelo fracasso de algumas tentativas comerciais de estúdios como a Fox, nos anos 50, no que diz respeito à criação de novos espaços sonoros. Essa nova distribuição de sons, construindo uma topografia inaudita, por vezes contrariava códigos preexistentes de relação entre sons e imagens. Nos anos 70, a partir do desenvolvimento de determinadas tecnologias de gravação e reprodução sonora, esse espaço é novamente modificado, trazendo uma riqueza maior de detalhes e suscitando uma afetação mais intensa dos corpos que o habitam. Inovações surgidas décadas antes são atualizadas e postas a trabalhar em função de um projeto imersivo mais amplo, alterando nossa relação com sons, objetos e o espaço à nossa volta.

Este trabalho procura analisar como a emergência dessas tecnologias, no âmbito do cinema, levou a uma reconfiguração do espaço de exibição, interferindo em modelos já estabelecidos de escuta. Dispositivos como o Dolby ou o THX - a própria ampliação de um modelo monofônico de reprodução para um modelo estéreo e, posteriormente, para um modelo de som surround - demonstram uma experiência pautada pela ideia de imersão. Novas mídias digitais criam novas demandas cognitivas que remetem constantemente a termos como velocidade, interatividade e conexão. Um maior engajamento do corpo é exigido por novos modelos comunicacionais. As ideias de cinema como evento (ALTMAN, 2004), de um novo espaço idealizado por tecnologias sonoras (CHION, 1994, 2007, 2009) ou de um espaço sonoro compacto (LANGKJÆR, 1997), nos ajudam a pensar esse novo cenário.

\section{Evolução dos dispositivos de imersão}

Vamos pensar, neste momento, como inovações tecnológicas - aqui, especificamente no âmbito do cinema - requerem uma nova conformação dos sentidos (na verdade, do corpo como um todo) para que se estabeleçam novas formas de cognição. Os contornos imersivos adquiridos pelo dispositivo cinematográfico ao longo do tempo demonstram isso claramente.

A chamada primeira revolução sonora no cinema se deu quando, em fins da década de 1920, este passou a incorporar elementos de áudio não executados ao vivo à sua projeção de imagens. Podemos considerar esse processo uma revolução porque o que era antes um corpo fantasmático, nos dizeres de Mary Ann Doane (1983), agora se tornava um corpo mais cheio e organicamente unificado. Essa organicidade deu-se, primordialmente, pelo sincronismo entre som e imagem. Em um primeiro instante, elegendo a fala como elemento principal desse sincronismo e, posteriormente, buscando recriar um universo em torno dessa fala que pudesse acomodá-la mais naturalmente dentro do discurso do filme.

Nas décadas de 1930 e 1940 o que se viu foi o império dos talking films, filmes cujo maior mérito era o de conseguir unir sincronicamente imagem e fala. Por conta desse império dos diálogos muito da agilidade da montagem, conseguida pelo esforço de cineastas como Griffith, ficou para um segundo plano. O tempo médio de duração dos planos em filmes americanos nessa época aumentou significativamente devido à dificuldade de montagem em sincronia de planos com som e imagem.

Gradualmente, a novidade do som sincronizado foi despertando menor comoção do público. Inovações como a moviola sonora, o negativo com 
numeração de bordo e a gravação do som não mais em discos, mas em negativos, possibilitaram uma nova redução do tempo médio de duração dos planos ainda na década de 1930.

A tendência rumo a uma edição mais rápida em meados dos anos 30 pode ser facilmente explicada como um desejo de muitas pessoas de voltar ao tipo de montagem comum à maioria dos filmes mudos norte-americanos nos anos 20, quando a média de duração dos planos girava em torno dos 5 segundos. Uma vez que as restrições da montagem de som foram resolvidas pela moviola sonora e pela numeração de bordo, eles se sentiram livres para voltar ao ritmo das edições dos filmes mudos, na medida em que a duração média das falas dos diálogos permitisse (SALT, 1985, p. 40).

Outros fatores, contudo, impediam o uso do som de maneira mais inovadora. Como John Belton (1992) nos esclarece, os próprios estúdios, já na década de 1950, investiam em inovações como a reprodução magnética do som (de melhor qualidade que a óptica) e as múltiplas pistas, cada uma reproduzindo diferentes sons em pontos distintos da sala de projeção. A própria Disney havia exibido seu desenho animado Fantasia com três pistas ópticas de som estéreo já em 1940.

Muito embora fosse defendido por alguns estúdios que sistemas como o Cinerama ou o CinemaScope obtivessem um efeito de realismo maior, nem todas essas inovações foram bem sucedidas. Em relação ao filme de 1953, O manto sagrado (The robe), de Henry Koster, apresentado em CinemaScope e com quatro pistas de som estéreo, afirmou Spyros Skouras, então presidente da Twentieth Century Fox: "No Manto sagrado vocês ouvirão vozes de anjos. E essas vozes virão do único lugar onde se espera que os anjos sejam vistos - bem sobre vocês" (SKOURAS apud BELTON, 1992, p. 161).

Esses sistemas, bem como outros, como o Todd-AO, utilizavam reprodução de som a partir de fitas magnéticas tocadas em um deck separado e em sincronia com a projeção. O CinemaScope usava quatro pistas diferentes (esquerda, direita, centro e surround). O Todd- $A O$ dispunha de seis canais de áudio. Por serem grandes formatos de imagem, normalmente $70 \mathrm{~mm}$, e por necessitarem de um aparato mais sofisticado para exibição, esses sistemas muitas vezes restringiam-se aos espaços mais elitizados. Apesar da qualidade superior de som, as fitas magnéticas tinham a desvantagem de se desgastar mais rapidamente do que pista óptica na película. Não era raro que, depois de várias exibições, o som começasse a apresentar um grau razoável de degradação. De qualquer maneira, todos esses formatos apresentavam uma ideia de realismo que muitas vezes superava o próprio real. A expansão dos limites das telas e dos limites do espaço sonoro representava uma busca por novas dimensões da experiência cinematográfica.

O custo de implantação desses dispositivos certamente desestimulou sua disseminação mais ampla. Mas, da mesma maneira, o entender do público médio quanto ao que poderia ser considerado "realismo" também demonstrava certa dose de incerteza em relação às projeções em vários canais, coloridas e em telas gigantescas. Não pareciam naturais. Mesmo o filme colorido, curiosamente, também era tido como algo "artificial" pelo espectador, sendo associado, usualmente, a gêneros não realistas.

Significativamente, todos os desenvolvimentos tecnológicos discutidos anteriormente não eram identificados apenas com o realismo, mas também com o espetáculo. A atenção do público era dirigida para a novidade do aparato em si. O "maior realismo" produzido pela nova tecnologia era entendido, ao que parece, como um excesso, sendo, então, classificado como espetáculo (BELTON, 1992, p. 160).

Os estúdios, a partir de determinado momento, passaram a descartar o uso de alguns desses novos modelos por razões não só econômicas. O diálogo era reproduzido em mono. A MGM, a Warner e a Columbia recusavam-se a usar efeitos de "pingue-pongue" nesse que era um dos elementos narrativos mais atrelados a certa ideologia do visível (DOANE, 1985). Se era complicado manter uma relação paritária entre posicionamento de câmeras e de microfones sem, com isso, perder-se boa parte da inteligibilidade do que era dito, imagine distribuindo-se as falas em mais canais. Mais grave ainda, imagine-se esse diálogo reproduzido pelos 
canais surround, com vozes partindo das laterais e do fundo da sala de exibição. Os estúdios passaram a minimizar a importância desse canal (o surround), sendo que a Columbia nunca o usou.

De qualquer forma, esse novo "olhar" sobre a reprodução do som nos filmes, que começa a germinar na década de 1950, vai esperar vinte anos para finalmente encontrar respaldo na indústria e no mercado. Algumas dessas inovações foram trazidas da indústria fonográfica e adaptadas ao cinema por nomes como Robert Altman. As gravações multipistas, o uso de filtros como o Dolby e outras inovações encontram nas décadas de 1970 e 1980 um campo fértil para o desenvolvimento e para a experimentação.

O processo de síntese de novos sons, a partir de inovações dos anos 50, facilitou um domínio sobre frequências antes impensadas de modo isolado. A tecnologia permitiu melhor definição de graves e agudos, e mais potência. O curioso é perceber como, apesar de um discurso eminentemente lógico e científico que fomentou o desenvolvimento de novas tecnologias de reprodução e síntese sonora, foi a indústria do entretenimento que levou às últimas consequências a afetação dos corpos por esse novo tipo de sonoridade.

Na década de 1930 a MGM havia desenvolvido um sistema de alto-falantes de duas vias, o Shearer two-way horn system, que podia reproduzir de maneira mais eficiente as frequências altas e baixas. A fidelidade sonora, então, já era uma questão colocada no processo de gravação e reprodução do som nas salas de cinema. O uso dessas recentes tecnologias, porém, permaneceu bastante conservador, apesar de seu rápido desenvolvimento desde a década de 1930. A própria Academia de Cinema sugeria uma curva de frequências a ser observada na reprodução sonora que mal cobria o espectro de $150 \mathrm{~Hz}$ a $3 \mathrm{kHz}$ em uma potência próxima de $0 \mathrm{~dB}$ (amplitude máxima de reprodução sem distorção). Mais tarde, com o uso do Dolby, é proposto um novo modelo de curva (a curva $\mathrm{X}$ ), com o qual se poderia obter uma resposta mais eficiente, tanto de espectro quanto de potência.

$O$ som ainda era visto como elemento secundário pelos exibidores que não se sentiam à vontade para investir em melhorias que, além de mudarem constantemente, significavam maiores gastos. "A faixa de frequências e a qualidade do som na maioria dos cinemas não era muito melhor que o de telefones e continuou assim até metade dos anos 70, até a chegada do Dolby" (SERGI, 2004, p. 14).

\section{Dolby, Sensurround, THX: novos espaços sonoros}

Ray Dolby, antes de fundar os Laboratórios Dolby, já havia trabalhado e contava com uma boa experiência na gigante Ampex, trabalhando na área de novas tecnologias de áudio e vídeo. Ele desenvolveu, no início da década de 1970, um sistema de redução de ruídos e ampliação do espectro sonoro nos filmes. O Dolby A vinha sendo utilizado na indústria fonográfica e Ray Dolby acreditava que poderia ser bastante útil na redução do ruído de fundo proveniente das várias etapas de pós-produção de filmes. Sua grande preocupação nesse momento em relação ao cinema era, além de tentar melhorar o processamento desse áudio na finalização, treinar técnicos de som para que estes pudessem obter melhores resultados nos momentos de captação e mixagem. Em 1971, Laranja mecânica (A clockwork orange, Stanley Kubrick) foi um dos primeiros filmes a utilizar o Dolby A, mas não ainda da forma e com o impacto que tornariam o processo um padrão de reprodução sonora do cinema americano e mundial. Mais tarde, Dolby interessou-se por como esse som era reproduzido nas salas de exibição. Além da redução de ruídos e distorção, tentou aumentar a faixa de frequências alcançada pela limitada pista óptica (padrão de reprodução sonora na maioria dos cinemas). Tão importante quanto: tentou ampliar as possibilidades do som óptico de uma pista monofônica para quatro pistas, três frontais e uma lateral. Utilizando uma pista óptica dupla, o Dolby Stereo trazia, além da informação dos canais esquerdo e direito, um canal central e um surround, cuja função era disfarçar o entorno da sala, fornecendo som ambiente e efeitos especiais. Os canais central e surround são codificados e inscritos nos mesmos canais ópticos esquerdo e direito, porém com diferenças em relação à fase e ao ganho do sinal. Assim, decodificadores no ato da projeção identificam esse sinal modificado específico e o direcionam para os alto-falantes próprios. Criava-se, dessa forma, um espaço sonoro ampliado que conferia às próprias imagens uma vida para além do que a tela poderia mostrar. 
O Dolby não necessitava de grandes investimentos por parte dos exibidores. Possuía alguma compatibilidade com projetores antigos e com o som óptico padrão. Só restava identificar para que tipo de filme exatamente esse novo modelo de som serviria. Musicais foram uma primeira aposta dos estúdios. Tommy (Ken Russel, 1975) e Nasce uma estrela (A star is born, Frank Pierson, 1976) foram alguns dos filmes que testavam o potencial dessa nova tecnologia. Mas ainda havia mais a explorar.

Ray Dolby e a indústria cinematográfica perceberam, com Guerra nas estrelas (Starwars, George Lucas, 1977), que lidavam com um novo modelo de experiência fílmica. Tanto é que Guerra nas estrelas é considerado por muitos como o "Cantor de jazz" do Dolby: aquele filme que chamou atenção para o fato de que havia uma outra maneira de se pensar a experiência sonora no cinema. As plateias poderiam ser sensibilizadas de uma forma diferente do que vinha sendo feito por uma narrativa clássica logocêntrica. A ideia de reconstrução do espaço sonoro, já dissemos, não era nova, mas havia, dessa vez, algo que favorecia a aceitação pelo público de novas dimensões perceptivas do filme. Os efeitos especiais, a potência do som, sua distribuição em vários pontos da sala, exerciam, agora, fascínio sobre a plateia.

A cópia em $70 \mathrm{~mm}$ de Guerranas estrelas, além das quatro pistas de som (magnético, não óptico), possuía um tipo de codificação para dar ênfase a sons subgraves (sons abaixo dos $30 \mathrm{~Hz}$, que possuem um impacto grande sobre o corpo, fazendo-o vibrar), produzindo uma sensação de envolvimento físico do espectador com a narrativa.

Para Michel Chion, o Dolby cria um espaço com bordas fluidas, "um tipo de supertela envolvendo a tela" (CHION, 1994, p. 69). Ao expandir nossa audição a faixas de frequências mais altas e mais baixas, ao possibilitar a reprodução de sons com uma maior riqueza harmônica, ele criou uma nova forma de o cinema se expressar por meio de sons. O espaço estendeu-se em todas as direções. Do tutti sonoro ao pianíssimo, como em uma grande orquestra. Ao mesmo tempo em que possibilitava a reprodução de sons graves, explorando sonoridades intensas, o Dolby reduzia significativamente o ruído de fundo da reprodução. Abria-se para o público um modelo de exibição em que o impacto de sons poderosos convivia com o silêncio dos alto-falantes. Como diz Chion (2007, p. 151): o Dolby introduz, deste modo, um novo elemento expressivo: o silêncio dos altofalantes, acompanhado de sua reflexão, o silêncio atento da plateia. Qualquer silêncio nos faz sentir expostos, como se estivéssemos deixando nua nossa própria audição, mas também com se estivéssemos na presença de um ouvido gigantesco, consciente de nossos próprios e diminutos ruídos. Nós não estamos mais apenas ouvindo um filme, nós estamos como que sendo igualmente ouvidos por ele.

Assim como o excesso sonoro apresentado pelo Dolby e por outros melhoramentos técnicos nos processos de gravação, mixagem e reprodução nos apresentam um desafio de sempre descobrir novos detalhes a cada audição, também o silêncio quase total - igualmente possibilitado pelo Dolby - testa nossa capacidade de ouvir.

Para Chion, as mudanças tecnológicas dos anos 70 e 80 tornaram o trato sonoro mais analítico, separando bem os espaços entre cada som e entre os sons e a ausência dele. O Dolby SR (Spectral Recording) implementado nos anos 90, a partir da evolução dos modelos anteriores, garantiu uma ainda melhor definição dos diferentes espectros de frequências. Garantiu, assim, que o espaço sonoro, cada vez mais repleto de elementos, pudesse contar com uma melhor distribuição. Sua capacidade de aumentar a faixa dinâmica (diferença entre os sons mais e os menos intensos) e de reduzir o ruído de fundo em até $25 \mathrm{~dB}$ foram feitos notáveis.

Podemos atribuir a importância do Dolby à sua capacidade de manter-se compatível com tecnologias anteriores, como projetores com reprodução óptica de som. $O$ formato tradicional da reprodução sonora das cópias em $35 \mathrm{~mm}$ dos filmes utilizando Dolby ainda era o som óptico. Hoje, mesmo com o advento de cópias com reprodução sonora digital, ainda mantém-se a compatibilidade com esse modelo analógico, preservando-se a trilha óptica ao lado dos fotogramas na película.

Ao trazer os detalhes para próximo do espectador, o Dolby alimenta a relação de intimidade entre filme e plateia. Sussurros são claros, a respiração não se esconde sob os ruídos. Estamos atentos a sutilezas materiais agora tornadas portadoras de sentidos. O que antes era descartado como se desprovido de 
significância, agora é importante para compreender outras dimensões do filme. As condições materiais de gravação e reprodução cada vez nos interessam mais. "Todos esses ruídos táteis, leves, o cinema não se contenta mais em dar a eles, como anteriormente, uma tradução ruidosa impessoal, ele lhes oferece uma presença verdadeira, uma matéria, uma identidade" (CHION, 1988, p. 34).

Outro tipo de experiência, desenvolvida nos anos 70, exemplar dessa nova relação entre sons, espaços e sensibilização física do espectador foi o Sensurround. O sistema Sensurround foi desenvolvido pela Universal para o lançamento, em 1974, do filme Terremoto (Earthquake, Mark Robson). Apesar de não ter sido totalmente bem-sucedido, o sistema chegou a ser usado em filmes posteriores como $A$ batalha de Midway (Midway, Jack Smight, 1976) e Rollercoster (James Goldstone, 1977). O sistema contava com grandes subwoofers Cerwin-Wega, posicionados sob a tela e amplificados com 1.600 Watts de potência. Frequências em torno de $40 \mathrm{~Hz}$ eram reproduzidas com uma pressão sonora de 110-120 dB. Outras frequências, abaixo inclusive do limite humano de escuta $-20 \mathrm{~Hz}$ (infrasons) -, eram também acentuadas.

Parte desses sons graves era gerada eletronicamente em equipamentos especiais, ao comando de sinais específicos na trilha de som óptico do filme. Alguns sons, efetivamente gravados e reproduzidos na pista de som convencional, também eram enviados para esses alto-falantes especiais.

O sistema chegou a causar danos estruturais em alguns prédios próximos às salas de exibição. Objetos como lustres e cadeiras tremiam no cinema e houve mesmo relatos de ferimentos em espectadores. Em uma segunda versão, o Sensurround II, era prevista a reprodução de frequências de até $15 \mathrm{~Hz}$. A pressão sonora era tamanha que muitos alto-falantes foram danificados. Caiu em desuso a partir da popularização de sistemas mais práticos como o Dolby.

De qualquer maneira, a manipulação de sons, seja no ato da gravação, da edição ou da mixagem, seja pela síntese de novos timbres por meios eletrônicos ou pela manipulação de parâmetros físicos como, por exemplo, o incremento das frequências mais graves por sintetizadores subarmônicos, é fato corriqueiro na produção cinematográfica. O som de um filme, especialmente os de grande apelo sinestésico, é a reconstrução de uma realidade - mais real que o real - por meio de novas tecnologias, herdeiras de um pensamento científico, mas visando uma excitação sensorial.

O gênero ficção científica e, de um modo geral, os filmes de ação souberam bem aproveitar as novas dimensões criadas pelas novas tecnologias de som. Não apenas o fato de termos um som mais potente, abrangente e claro, mas também o fato desse som criar novos espaços na sala de exibição. A configuração desse espaço sonoro, claro, ainda é atrelada a uma série de convenções - principalmente aquelas que dizem respeito ao grau de inteligibilidade da narrativa - mas o fato de novos modelos de reprodução multicanal permitirem um nível maior de imersão, favoreceu a emergência de um cinema espetacular e calcado nas sensações.

A chegada do som digital possibilitou um aumento sensível da qualidade de som em espaços que não estavam dispostos a (ou não tinham condições de) investir em equipamentos adicionais de reprodução sonora. A década de 1990 viu a chegada, ao mercado, de alguns sistemas que apostavam na clareza e na ausência de ruídos de fundo do formato digital.

O padrão THX foi desenvolvido na década de 1980 pela Lucasfilm, não apenas como uma tecnologia som, mas para tentar uniformizar de vez o que era visto e ouvido nas salas de cinema em qualquer lugar do mundo. Sendo assim, o sistema inclui não apenas uma certificação para determinados tipos de aparelhos de projeção ou amplificação e reprodução de som, mas todo um conjunto de modificações arquitetônicas visando um melhor aproveitamento dessas tecnologias. Novamente, como já vimos no processo de eletrificação dos cinemas e teatros americanos na década de 1930, o som estava nas mãos da tecnologia, pelo menos aparentemente.

\section{O espaço sonoro compacto}

O conceito de identificação, como apresentado por Noël Carroll (apud LANGKJÆR, 1997), diz que não sentimos o mesmo que o personagem. Há uma separação entre os sentimentos da plateia e os que são demonstrados na tela. Nesse processo de assimilação, modelo padrão de recepção pelo público, nós sentimos pelo protagonista e não como o 
protagonista. Nossas respostas são sempre mediadas por uma empatia com os personagens.

Por outro lado, Birger Langkjær cita a ideia de que o público pode se imaginar sentindo as mesmas emoções dos personagens. Essa mimese involuntária é uma situação imaginada, uma emoção paralela à encontrada na tela, mas é sentida como real. A implicação emocional transforma o tipo de relação com os papéis que vemos no filme, "como se os eventos dissessem respeito a nós mesmos e não apenas a personagens fictícios. A emoção não é mais assimilada, mas verdadeiramente sentida em nossa mente corporificada" (LANGKJÆR, 1997, p. 101).

A hipótese aventada por Langkjær é a de que o espaço ampliado por tecnologias de distribuição sonora no ambiente de exibição favorece essa sensação de realidade, mesmo que tenhamos consciência de que se trata de uma situação imaginada. Essa sobrecarga perceptual (e emocional) dá-se em função de um espaço sonoro compacto, em que o aspecto perceptual da experiência é deixado em aberto, não havendo uma definição ou síntese satisfatória das informações captadas pelos sentidos. O espaço é constantemente varrido pelos sentidos e, à medida que novos detalhes acústicos se apresentam, ele se reconstrói continuamente, deixando um nível de incerteza quanto ao mapeamento desse território. A relação entre a bidimensionalidade (que simula uma tridimensionalidade) da imagem e a real tridimensionalidade desse novo espaço sonoro (que, muitas vezes, se oculta para não questionar o espaço visível) são peças-chave para compreendermos os efeitos de identificação do espectador.

Langkjær identifica uma assimetria entre as ideias de ponto de vista (POV) e ponto de audição (POA). Enquanto é fácil assimilarmos o ponto de vista como uma relação entre a câmera e o objeto, o mesmo não se dá com o ponto de audição. Mesmo quando define duas formas de entendermos o ponto de vista - como o lugar de onde o espectador observa ou como o lugar de onde um determinado personagem igualmente vê o que acontece na açãoMichel Chion não deixa de enxergar como mais óbvia essa dinâmica específica da imagem do que aquela correspondente ao som. Quando tentamos transpor esses tipos de referências para o universo sonoro a situação se complica. Para o autor, a natureza omnidirecional do som não permite que se delimite um local específico de onde nós ou algum personagem esteja ouvindo. "Não é frequentemente possível falar-se de um ponto de escuta no sentido de uma posição precisa no espaço, mas, em vez disso, de um lugar de escuta, ou mesmo zona de escuta" (CHION, 1994, p. 91).

Para Chion (1994, p. 91) a noção de um ponto específico no espaço diegético estaria necessariamente atrelada à imagem. "É a representação visual do personagem em close-up que, em uma associação simultânea com a escuta do som, identifica esse som como sendo escutado pelo personagem mostrado". Rick Altman compartilha dessa opinião de que o ponto de escuta resulta de uma combinação de som e imagem, dizendo que ele "constitui a interpelação perfeita, pois nos insere na narrativa justamente na interseção de dois espaços que a imagem, sozinha, seria incapaz de ligar, dando-nos, então, a sensação de controlarmos a relação entre esses espaços" (ALTMAN, 1992, p. 60-61). O ponto de escuta nos retiraria a liberdade de vasculhar aleatoriamente o espaço sonoro do filme, uma vez que somos atrelados a um lugar e a um objeto específico naquele momento.

Entretanto, para Langkjær, o que ocorre é uma relação perceptual entre os dois, em que o ponto de vista referencia-se por uma tridimensionalidade da visão e o ponto de escuta (em filmes monofônicos) apenas pela distância entre objeto e microfone. Muito embora, mesmo em sons provenientes de apenas uma fonte reprodutora no espaço de projeção, possamos admitir que, pelo menos nesse espaço, há uma direcionalidade evidente (a posição do alto-falante), essa segunda dimensão sonora é frágil e não questiona o espaço criado visualmente. O som monofônico funciona como se fosse um elemento uno, proveniente de todas as partes e, consequentemente, anulando as diferenças entre essas partes. $\mathrm{O}$ espaço reduz-se a uma única dimensão sonora e acaba, dessa forma, inevitavelmente, atrelado à imagem, maior responsável pela impressão de tridimensionalidade.

A tarefa de criar um espaço sonoro estável, porém, em uma nova relação entre o som estereofônico e a imagem é mais complicada. Cria-se um modelo espacial de um-para-um entre som e imagem, ou algo próximo disso. Assim, nos diz Langkjær, o som estereofônico - e posteriormente o surround - pode ser mais perturbador do que o som mono. $\mathrm{O}$ trabalho 
perceptivo para incorporar diferentes distâncias e localizações no espaço é maior com o estéreo. Então, para manter-se a atenção do espectador voltada para o que a imagem mostra, é necessário que pelo menos parte desse material sonoro esteja fixo, de maneira padronizada, em um ponto central. Os diálogos, de um modo geral, assumem essa função.

O fracasso de tentativas comerciais de filmes em estéreo na década de 1950 deu-se, parcialmente, pelo excesso na utilização do recurso que, muitas vezes, contrariava códigos narrativos já estabelecidos. Ao ser retomado, nos anos 70, o som estéreo traz consigo, além de um espaço mais amplo, uma riqueza de detalhes não concebida previamente. O Dolby possibilitou uma complexidade maior de sons audíveis. A quantidade de informação a ser compreendida e conscientemente separada das outras aumentou consideravelmente. Quando, antes, o diálogo e algum som ambiente, além dos ruídos pertencentes à diegese, eram mais do que suficientes para o preenchimento sonoro da ação, agora a riqueza de detalhes suscita novas dimensões a serem abarcadas. Aparentemente, o som exige, neste momento, uma maior atenção, podendo revelar detalhes sutis antes escondidos.

O uso estético do som de alta definição (incluindo o som digital) não conduziu necessariamente a um espaço sonoro mais facilmente distinguível. Em vez disso, parece que os designers de som estão inclinados a fornecer mais detalhes sonoros, deste modo empurrando a consciência sensorial na direção dos limites da percepção. Esse tipo de textura sonora extremamente densa é frequentemente difícil de ser dividida pelo ouvido e representa o que eu chamo de um espaço sonoro compacto (LANGKJÆR, 1997, p. 99).

Langkjær insere na ideia de espaço sonoro compacto a relação cambiante entre os processos cognitivos e os interesses emocionais do espectador. Fatores como a quantidade de informação sonora fornecida pelo filme e a capacidade perceptiva de quem se submete a essa informação são fatores importantes no processo de fruição do filme.

Igualmente importantes para novos processos cognitivos exigidos pelo cinema desse período são os sons sintetizados. Enquanto os efeitos sonoros utilizados anteriormente guardavam uma relação icônica ou indicial com uma determinada ação ou objeto, os novos sons passam também a mediar um vínculo emocional com o espectador. Eles adquirem uma expressividade que nunca foi possível quando tratados apenas como efeitos sonoros. O som foge do reconhecimento como um objeto específico e aproxima-se de uma função musical, no que diz respeito a criar climas e definir psicologicamente situações ou personagens. "É difícil de o espectador conceituar e, portanto, o elemento sonoro compacto individual funciona como uma excelente ferramenta para criar uma sobrecarga perceptual e emotiva" (LANGKJÆR, 1997, p. 103).

\section{Conclusão}

Podemos perceber o quanto o advento de novas tecnologias de som, principalmente aquelas que forneceram uma maior possibilidade de controle sobre a gravação e reprodução sonoras, contribuiu para um apelo mais intenso aos sentidos. Nesse caso, seguindo uma tradição sessentista de busca por novas formas de cinema (YOUNGBLOOD, 1970) e por novos estímulos sensoriais, o processo de complexificação do campo auditivo atendeu perfeitamente às exigências de um novo modelo de escuta.

A reconstrução do espaço sonoro no cinema estebeleceu novas bases para a compreensão da própria experiência cinematográfica. Não devemos deixar de considerar o quanto essas modificações sonoras imiscuiram-se em nossa própria relação com o mundo, como modificaram processos cognitivos tanto de ordem auditiva como aqueles envolvendo outros sentidos. O corpo responde integralmente a essa natureza imersiva do espaço sonoro, reconstruído e amplificado pelas tecnologias:

enquanto o filme da década de 30 cuidava da identificação visual e psicológica inconsciente do espectador com personagens que pareciam ser um perfeito amálgama de imagem e som, os anos oitenta anunciavam um novo tipo de identificação visceral, dependente da qualidade do sistema de som, através de graves potentes e efeitos sonoros inesperados, fazendo os 
espectadores vibrarem - quase literalmente com todo o espaço narrativo. Não são mais os olhos, os ouvidos ou o cérebro que sozinhos iniciam a identificação e mantém contato com a fonte sonora; em vez disso, é o corpo inteiro que estabelece essa relação, marchando ao som de um sistema diferente. Antes o som estava escondido por detrás da imagem, com o fim de estabelecer uma mais completa identificação com esta; agora o som chama atenção para si, mostrando uma identificação sonora separada e contestando o limitado e racional desenho da imagem e seus componentes visíveis (ALTMAN, 1995, p. 6).

Cabe, inclusive, a pergunta sobre a pertinência de ainda separarmos os processos perceptivos em modelos tão distintos. Se pudermos observar os modelos sensoriais sob outra luz - a de que o corpo, a mente e o próprio ambiente participam dos processos de cognição de formas igualmente importantes e, às vezes, pouco distintas - poderemos tentar nos aproximar de um constructo, literalmente, mais orgânico, em que a matéria inicia e referencia o percurso de criação de sentidos.

\section{Referências}

ALTMAN, R. (Ed.). Sound theory/sound practice. New York: Routledge, 1992.

ALTMAN, R. The sound of sound: a brief history of the reproduction of sound in movie theaters. 1995. Disponível em: <http://ifsstech.files.wordpress. com/2008/06/sound_of_sound_-_rick_altman.pdf $>$. Acesso em: 9 dez. 2008.

ALTMAN, R. Silent film sound. NewYork: Columbia University Press, 2004.

BELTON, J.1950s magnetic sound: the frozen revolution. In: ALTMAN, R. (Ed.). Sound theory/sound practice. New York: Routledge, 1992. p. 154-167.
CHION, M. La toile trouée: la parole au cinema. Paris: Cahiers du Cinéma, 1988.

CHION, M. Audio-vision: sound on screen. New York: Columbia University Press, 1994.

CHION, M. The silence of the loudspeakers, or why with Dolby sound it is the film that listen to us. In: SIDER, L.; FREEMAN, D.; SIDER, J. (Ed.). Soundscape: the school of sound lectures 1998-2001. London: Wallflower Press, 2007. p. 150-154.

CHION, M. Film, a sound art. New York: Columbia University Press, 2009.

DOANE, M. A. A voz no cinema: a articulação de corpo e espaço. In: XAVIER, I. (Org.). A experiência do cinema. Rio de Janeiro: Graal; Embrafilme, 1983. p. 457-475.

DOANE, M. A. Ideology and the practice of sound editing. In: WEIS, E.; BELTON, J. (Ed.). Film sound: theory and practice. New York: Columbia University Press, 1985. p. 54-62.

LANGKÆR, B. Spatial perception and technologies of cinema sound. Convergence: The International Journal of Research Into New Media Technologies, n. 3, p. 92-107, 1997. Disponível em: <http:/ / con.sagepub.com/cgi/content/abstract/3/4/92>. Acesso em: 9 dez. 2009.

SALT, B. Film style and technology in the thirties: Sound. In: WEIS, E.; BELTON, J. (Ed.). Film sound: theory and practice. New York: Columbia University Press, 1985. p. 37-43.

SERGI, G. The Dolby Era: film sound in contemporary Hollywood. Manchester; New York: Manchester University Press, 2004.

YOUNGBLOOD, G. Expanded cinema. New York: E. P. Dutton \& Co, Inc., 1970.

Recebido: 27/09/2011 Received: 09/27/2011

Aprovado: 27/10/2011

Approved: 10/27/2011 